\title{
Short-Term Effects of Atropine $0.01 \%$ on the Structure and Vasculature of the Choroid and Retina in Myopic Chinese Children
}

\author{
Yuliang Wang $\cdot$ Xingxue Zhu $\cdot$ Yi Xuan · Min Wang \\ Xingtao Zhou $\cdot$ Xiaomei Qu
}

Received: January 4, 2022 / Accepted: January 31, 2022 / Published online: February 20, 2022

(C) The Author(s) 2022

\begin{abstract}
Introduction: To explore the short-term effects of atropine $0.01 \%$ on the structure and vasculature of the choroid and retina in myopic Chinese children.

Methods: This study was a single-center randomized clinical trial. A total of 40 subjects with myopia $<-6.0 \mathrm{D}$ were enrolled and randomized to receive atropine $0.01 \%$ once nightly with regular single-vision lenses or to simply wear regular single-vision lenses at an allocation ratio of $1: 1$. Follow-up visits were planned at 1 month and 3 months. Choroidal thickness (ChT) was obtained by optical coherence
\end{abstract}

Yuliang Wang and Xingxue Zhu contributed equally as co-first authors.

Supplementary Information The online version contains supplementary material available at https:// doi.org/10.1007/s40123-022-00476-0.

Y. Wang $\cdot$ X. Zhu $\cdot$ Y. Xuan · M. Wang $\cdot$ X. Zhou . X. Qu ( $\square)$

Department of Ophthalmology and Vision Science, Eye \& ENT Hospital, Fudan University, Shanghai, China

e-mail: quxiaomei2002@126.com

Y. Wang $\cdot$ X. Zhu $\cdot$ X. Zhou . X. Qu

NHC Key Laboratory of Myopia, Fudan University, Shanghai, China

Y. Wang $\cdot$ X. Zhu $\cdot$ X. Zhou . X. Qu

Laboratory of Myopia, Chinese Academy of Medical

Sciences, Shanghai, China tomography (OCT). Retinal vessel density (RVD), retinal thickness (RT), foveal avascular zone (FAZ) and choriocapillaris flow (CCF) were measured by optical coherence tomography angiography (OCTA). The RVD and RT were measured at fovea, parafovea and perifovea area and four quadrants.

Results: Twenty-one subjects were allocated into the atropine group and 19 subjects into the control group. Over 3 months, the control group showed greater progression of myopia than those in the atropine group. ChT in the atropine group increased $11.12 \pm 13.96 \mu \mathrm{m}$, which was not significant compared with that of the control group. None of the retinal sectors in atropine-treated eyes showed significant changes of RT and RVD compared with the control group. Besides, FAZ and CCF of the atropine group were not affected by atropine use over time, and there was no difference between the two groups.

Conclusion: Administration of atropine 0.01\% eye drops demonstrated no effect on RVD, FAZ and CCF over 3 months, while a modest increase of ChT was observed in atropine-treated eyes.

Trial

Number: ChiCTR1800017154.

Registration

Keywords: Atropine; Choroid; Myopia; Retina; Vasculature 


\section{Key Summary Points}

\section{Why carry out this study?}

Myopia has become a significant public health concern globally in recent decades. Atropine $0.01 \%$ eye drops are considered an effective and safe treatment to control the progression of myopia. However, the effects of atropine $0.01 \%$ on structural and vascular characteristics of the retina and choroid in myopic children eyes remain unknown.

\section{What was learned from the study?}

The administration of atropine $0.01 \%$ eye drops showed no significant short-term effects on choriocapillaris flow, the thickness and vessel density of the retina and the foveal avascular zone. A modest but statistically non-significant increase of subfoveal choroidal thickness in the atropine-treated eyes at the 3-month visit was observed. This study confirmed the safety of atropine $0.01 \%$ on the choroidal and retinal structure and vasculature and suggested the need for further studies with larger samples and longer follow-up.

\section{INTRODUCTION}

Myopia has become a serious public health concern globally, owing to its widespread high prevalence [1], increasing risk of vision-threatening ophthalmic complications [2] and extra economic costs incurred for the treatment [3]. As the etiology of myopia remains unclear, the prevention of myopia progression has been prioritized. Low-dose atropine has been widely studied and is considered as an effective topical medication in myopia treatment [4].

The long-term use of a lower concentration of atropine (including 0.5\%, 0.25\% and 0.1\% atropine) all showed a significant protective effect regarding slowing myopia progression [5].
However, a dose-dependent rebound effect after cessation of treatment was noted in the Atropine for the Treatment of Childhood Myopia 2 (ATOM2) study, with atropine $0.01 \%$, the lowest dose of atropine tested, showing the least overall myopic progression [6]. Although the Low Concentration Atropine for Myopia Progression study recently indicated that the efficacy of atropine $0.05 \%$ was double that of atropine $0.01 \%$ in spherical equivalent (SE) progression over 2 years, atropine $0.01 \%$ is still considered as a promising approach balancing both efficacy and safety [7]. Besides, two recently published studies reported the efficacy of atropine $0.01 \%$ in the inhibition of axial elongation $[8,9]$, which is considered to be the primary means of minimizing risk of myopiaassociated pathologies [10]. Moreover, clinical trials designed to evaluate the efficacy and safety of atropine $0.01 \%$ eye drops in myopia control have been or are about to be conducted in different countries among multiple ethnic populations [11-16]. However, the underlying molecular mechanism of the suppressive effect of this anti-myopia agent remains unknown, and a sophisticated clinical practice guideline on atropine therapy requires more relevant studies.

In recent years, researchers have had an everincreasing interest in the role of the choroid and the retina in the etiology of myopia, as the choroid was found capable of reacting to optical defocus with the bidirectional changes in thickness [17], and the retina was expected to process the sign of optical defocus and produce a multilayered signaling cascade from the retina to the choroid and then to the sclera [18]. The advent of optical coherence tomography (OCT) allowed in situ imaging of intraocular microstructures with high resolution and detailed delineation of the spatial relationship between multiple layers at the posterior pole. In addition to structural changes, both the retinal and choroidal vascular parameters have attracted great interest in the last 2 decades, as retinal arteries supplying the inner retina and choroidal blood vessels nourishing the outer retina and the vasculature are closely related to the structure and function. Optical coherence tomography angiography (OCTA) provides 
non-invasive visualization of the retinal and choroidal vasculature and generates relevant data on anatomic features and perfusion status [19].

To the best of our knowledge, few studies have revealed the effects of atropine $0.01 \%$ on structural and vascular characteristics of the retina and choroid in myopic eyes. In this study, we aim to evaluate the short-term influence of atropine $0.01 \%$ eye drops on structural and vascular parameters of the choroid and retina to further evaluate the effects of atropine $0.01 \%$ and identify potential biomarkers for predicting therapeutic responses.

\section{METHODS}

This study was a single-center randomized clinical trial conducted at the Eye \& ENT Hospital of Fudan University, Shanghai, China, from January 2019 to September 2019. The study was approved by the Ethics Committee of the Eye \& ENT Hospital of Fudan University and conducted in accordance with the tenets of the Declaration of Helsinki. Written informed consent was obtained from the parents or legal guardians of all enrollees, and either written or verbal assent was obtained from each participant. The study is listed at www.chictr.org.cn under identifier ChiCTR1800017154.

We estimated that enrollment of 40 subjects would provide the study with $90 \%$ power to detect an increase of $15 \mu \mathrm{m}$ in subfoveal choroidal thickness as the primary end point in the atropine group compared with the control group, assuming an increase of $5 \mu \mathrm{m}$ at 3-month visit, at an alpha significance level of 0.05. Children aged 6-14 years who met the eligibility criteria listed in Table S1 were enrolled. The enrollees were assessed at a screening visit and then randomized at an allocation ratio of $1: 1$ to receive atropine $0.01 \%$ once nightly with regular single-vision lenses or to just wear regular single-vision lenses. As atropine $0.01 \%$ is not commercially available in China, the eye drops were prepared by the Pharmaceutical Department of Eye \& ENT Hospital [0.05\% atropine sulfate $(1 \mathrm{ml})$ in poly(ethylene glycol) eye drops $(4 \mathrm{ml})]$ [20].
All participants underwent a standardized examination at the baseline visit and two follow-up visits planned at 1 and 3 months. Cycloplegic refraction was used to assess the refractive errors before enrollment. Cycloplegia was achieved with four drops of compound tropicamide eye drops $(0.5 \%$ tropicamide and $0.5 \%$ phenylephrine eye drops; Mydrin-P, Santen Pharmaceutical, China), administered approximately $5 \mathrm{~min}$ apart. Cycloplegic autorefraction was measured $30 \mathrm{~min}$ after the last drop using a desktop autorefractor (KR-8800, Topcon Corporation, Japan). Three readings, $\leq 0.25 \mathrm{D}$ apart, in both the spherical and cylindrical components were averaged. Cycloplegic retinoscopy was then performed by an experienced optometrist, and BCVA was measured at a distance of $4 \mathrm{~m}$ and converted to the logarithm of the minimum angle of resolution (logMAR) scale. Before cycloplegia, axial length (AL), anterior chamber depth (ACD), lens thickness (LT), central corneal thickness (CCT) and keratometric values were measured with IOL Master 700 (Version 5, Carl Zeiss Meditec, Jena, Germany). Keratometry values were recorded as K1 (flat keratometry), K2 (steep keratometry) and $\Delta \mathrm{K}$ (corneal astigmatism).

OCT and OCTA measurements were obtained about $1 \mathrm{~h}$ after cycloplegia. All OCT measurements were completed at a similar time of day between 12 a.m. and 3 p.m. to limit the potential confounding influence of diurnal variations in choroidal thickness. ChT was performed by one experienced operator using SDOCT (Spectralis, Heidelberg Engineering, Germany) with the EDI mode. One hundred frames of fovea-centered, 6-mm horizontal and vertical OCT images were stacked for B-scan using the automatic real-time averaging and eye tracking features. Only OCT images with quality index $>$ $26 \mathrm{~dB}$ were included for further analysis. Two experienced ophthalmologists masked to the ocular parameters of the participants independently analyzed the images by using the Heidelberg Eye Explorer software to manually measure ChT as the perpendicular distance between the hyper-reflective line of the retinal pigment epithelium (RPE) and the choroidal/ scleral border at the subfovea. ChT was recorded as the average of two values defined by two 
observers, and the measurement was checked by one senior observer who gave the final adjudication when the difference in two ChT values of the same image exceeded the mean value by $15 \%$.

The OCTA scans were obtained using AngioVue OCTA system (RTVue XR Avanti, Optovue, Inc., Fremont, CA, USA). Each $6 \mathrm{~mm} \times 6-\mathrm{mm}$ OCTA image centered at the fovea contains $304 \times 304$ pixels created from the intersection of the 304 vertical and 304 horizontal A-lines. The full retinal thickness was measured from the inner limiting membrane (ILM) to RPE. The retinal thickness (RT) of the fovea, parafovea and perifovea area, as defined by the Early Treatment Diabetic Retinopathy Study (ETDRS), was calculated separately in four quadrants [temporal (T), superior ( $\mathrm{S}$ ), nasal (N) and inferior (I)]. ETDRS areas include the foveal area (within central 1-mm diameter), the parafoveal area (from an inner diameter of $1 \mathrm{~mm}$ to an outer diameter of $3 \mathrm{~mm}$ ) and the perifoveal area (between the 3 and $6 \mathrm{~mm}$ concentric ring). The superficial capillary plexus layer of the retina (SCP) was automatically defined with the upper border as ILM and the lower border as inner plexiform layer (IPL) with an interface offset of $-9 \mu \mathrm{m}$, while the deep capillary plexus layer of the retina (DCP) was defined with the upper border as IPL with an interface offset of $-9 \mu \mathrm{m}$ and the lower border as outer plexiform layer (OPL) with offset of $9 \mu \mathrm{m}$. The retinal vessel density (RVD) of two layers was defined as percentage area occupied by vessels. AngioVue automatically segments the choriocapillaris layer from $9 \mu \mathrm{m}$ below to $31 \mu \mathrm{m}$ above Bruch's membrane, and the choriocapillaris flow (CCF) was calculated as the average flow signal by automatic analysis function in a selected area of $3.142 \mathrm{~mm}^{2}$ centered on the fovea. The foveal avascular zone (FAZ) was calculated automatically in $\mathrm{mm}^{2}$ by the software using the non-flow measure function on the retina en face image, which was segmented with an inner boundary at ILM and an outer boundary set at $9 \mu \mathrm{m}$ beneath OPL.

Only the right eye of each subject was included in the analyses. Primary outcomes include structural and vascular parameters of choroid and retina over 3 months. Secondary outcomes were changes of $\mathrm{SE}$ and $\mathrm{AL}$ from baseline to 3 months. A change in a parameter was defined as the difference between the baseline value and the corresponding follow-up value. At baseline, a two-sample t-test or the Mann-Whitney $U$ test was used to test the group differences in continuous data, and a $\chi^{2}$ test and Fisher's exact test were used in categorical data. A repeated-measure analysis was performed for the longitudinal data on ophthalmic parameters between two groups. The measurement reproducibility of the ChT between two observers at each visit was assessed using the method described by Bland and Altman [21]. Correlation analyses were assessed by Pearson correlation or Spearman's rank correlation. Multiple linear regression analyses were performed to explore significant independent variables that predicted changes in AL. A statistical significance level of 0.05 was used throughout the analysis. All statistical tests were performed with STATA 13.0 (College Station, TX, USA).

\section{RESULTS}

A total of 48 participants were assessed for their eligibility, and 40 participants were finally recruited to the study: 21 participants were allocated to the atropine group and 19 to the control group. One participant in the control group withdrew before 3-month visit.

\section{Distributions of Structural and Vascular Pattern of the Choroid and Retina at Baseline Visit}

The baseline characteristics of all participants are summarized in Table 1, and a gender-stratified analysis is presented in Table S2. Means of ChT in 6-8-year-old, 9-11-year-old and 12-14year-old children were $253.22 \pm 48.40 \mu \mathrm{m}$, $243.33 \pm 41.70 \mu \mathrm{m}$ and $220.47 \pm 36.40 \mu \mathrm{m}$, respectively (Table S3). On the other hand, ChT in mild $(-3.00 \mathrm{D} \leq \mathrm{SE} \leq-0.50 \mathrm{D})$ was larger than that in moderate myopes $(-6.00 \mathrm{D} \leq$ $\mathrm{SE}<-3.00 \mathrm{D})$ myopes $(234.71 \pm 40.75$ vs. $227.71 \pm 57.19 \mu \mathrm{m}, P=0.80$ ) (Table S4). However, neither ChT stratified by age nor refraction error showed significant difference. 
Table 1 Baseline values of primary ocular biometric parameters of two study groups

\begin{tabular}{llll}
\hline & $\begin{array}{l}\text { Atropine group } \\
\text { Mean }(\mathbf{S D}), \boldsymbol{N}=\mathbf{2 1}\end{array}$ & $\begin{array}{l}\text { Control group } \\
\text { Mean }(\mathbf{S D}), \boldsymbol{N}=\mathbf{1 9}\end{array}$ & $\boldsymbol{P}$ value \\
\hline Age $($ years $)$ & $9.90(1.58)$ & $9.89(1.94)$ & 0.99 \\
Female, $n(\%)$ & $8(38.1)$ & $12(63.2)$ & 0.11 \\
SE $(\mathrm{D})$ & $-2.38(1.46)$ & $-2.36(1.87)$ & 0.73 \\
AL $(\mathrm{mm})$ & $24.45(1.06)$ & $24.70(0.93)$ & 0.43 \\
BCVA $(\operatorname{logMAR})$ & $0.01(0.03)$ & $0.00(0.00)$ & 0.09 \\
K1 $(\mathrm{D})$ & $42.79(1.74)$ & $42.27(0.81)$ & 0.50 \\
K2 $(\mathrm{D})$ & $43.99(1.94)$ & $43.64(1.06)$ & 0.69 \\
$\Delta$ K $(\mathrm{D})$ & $-1.21(0.47)$ & $-1.37(0.66)$ & 0.87 \\
CCT $(\mu \mathrm{m})$ & $548.24(36.79)$ & $534.63(29.32)$ & 0.21 \\
ACD $(\mathrm{mm})$ & $3.80(0.18)$ & $3.75(0.17)$ & 0.32 \\
LT $(\mathrm{mm})$ & $3.42(0.14)$ & $3.37(0.13)$ & 0.18 \\
ChT $(\mu \mathrm{m})$ & $249.98(38.26)$ & $230.53(45.53)$ & 0.15 \\
CCF $\left(\mathrm{mm}{ }^{2}\right)$ & $2.15(0.11)$ & $2.20(0.10)$ & 0.18 \\
RT-Fovea $(\mu \mathrm{m})$ & $244.33(16.93)$ & $238.26(13.69)$ & 0.22 \\
sRVD-Fovea $(\%)$ & $21.01(7.43)$ & $19.25(6.05)$ & 0.42 \\
dRVD-Fovea $(\%)$ & $37.20(8.03)$ & $35.24(6.23)$ & $0.29(0.08)$ \\
FAZ $\left(\mathrm{mm}{ }^{2}\right)$ & $0.26(0.12)$ & 0.40 \\
\hline
\end{tabular}

$S E$ spherical equivalent, $A L$ axial length, $B C V A$ best corrected visual acuity, $K 1$ flat keratometry, $K 2$ steep keratometry, $\Delta K$ corneal astigmatism, $C C T$ central corneal thickness, $A C D$ anterior chamber depth, $L T$ lens thickness, $C h T$ choroidal thickness, $C C F$ choriocapillaris flow, $R T$-Fovea retinal thickness of the fovea region, $s R V D$-Fovea foveal vessel density of the superficial retinal layer, $d R V D$-Fovea foveal vessel density of the deep retinal layer, $F A Z$ foveal avascular zone

As for RT, the central fovea area was the thinnest of the three macular regions $(241.45 \pm 15.59 \mu \mathrm{m})$, and the RTs of the parafovea and perifovea regions were $315.73 \pm 11.64$ and $278.93 \pm 11.04 \mu \mathrm{m}$. The RT varied across quadrants within these two regions. The superior quadrant was the thickest of the parafovea area, followed by nasal, inferior and temporal quadrants. In the perifovea area, the thickest region was the nasal quadrant, followed by superior, inferior and temporal quadrants (Fig. 1).

The RVD also varied across regions and quadrants in two retinal layers. The parafoveal vessel density of the superficial retinal layer
(sRVD) was $49.48 \pm 4.01 \%$, which was the highest of all three ETDRS grids, followed by perifoveal $(48.47 \pm 2.25 \%)$ and foveal $(20.18 \pm 6.79 \%)$ regions. Similarly, the vessel densities of the deep retinal layer (dRVD) in the parafovea region $(53.20 \pm 4.13 \%)$ were higher than in the perifovea $(45.38 \pm 5.09 \%)$ and the foveal area $(36.27 \pm 7.21 \%)$. There was not a regular pattern of sRVD and dRVD among different quadrants (Fig. 1). However, sRVD was significantly correlated with dRVD in the foveal region $(P<0.0001)$, temporal quadrant of parafoveal region $(P=0.0283)$, perifoveal region $(P=0.0069)$ and superior quadrant $(P=0.0002)$ 

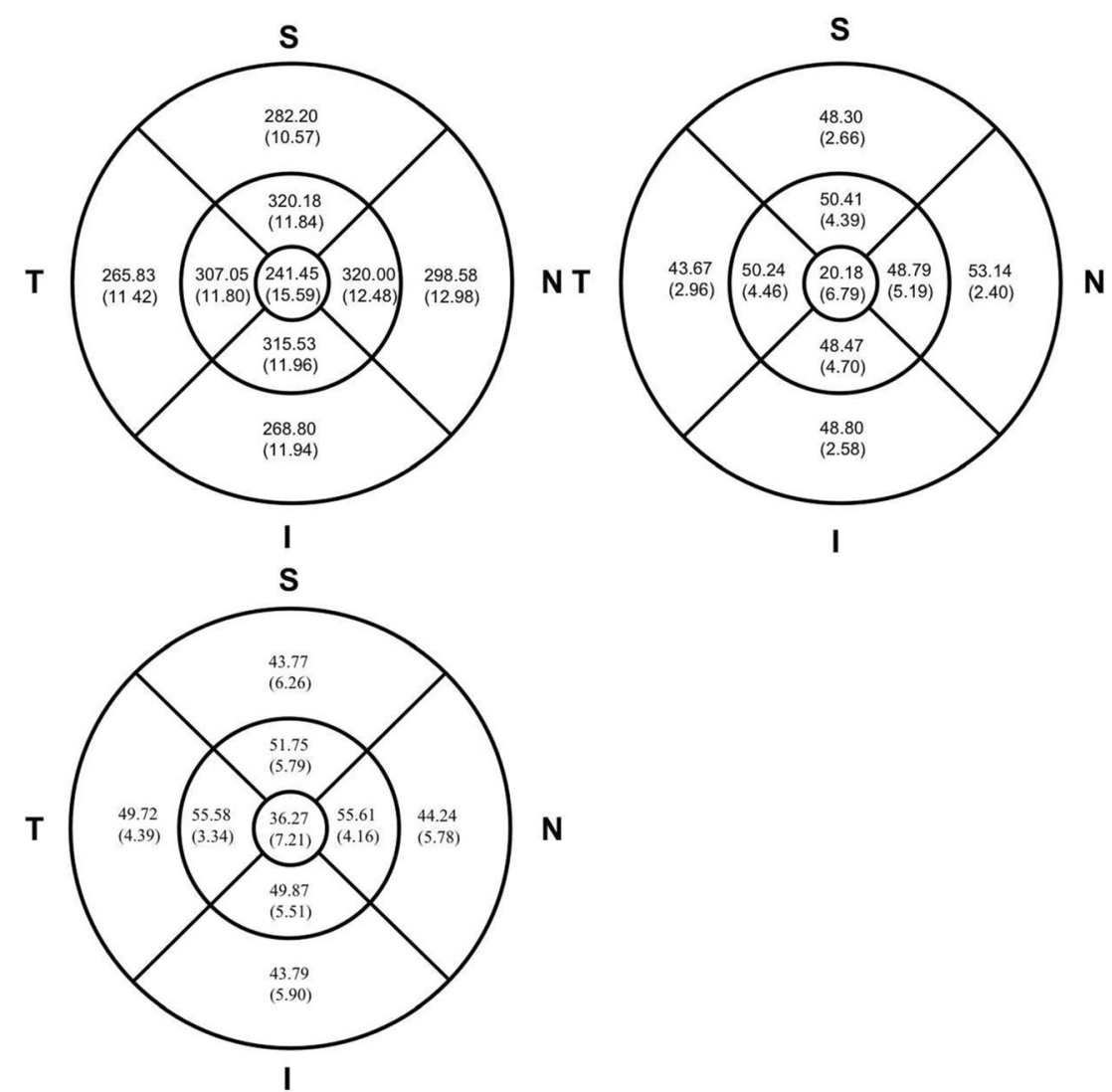

Fig. 1 Variation of the whole retinal thickness (top left), retinal vessel density of superficial capillary plexus layer (top right) and deep capillary plexus layer (bottom Left) in overall subjects at baseline. $S$ superior, $N$ nasal, $I$ inferior, $T$ temporal
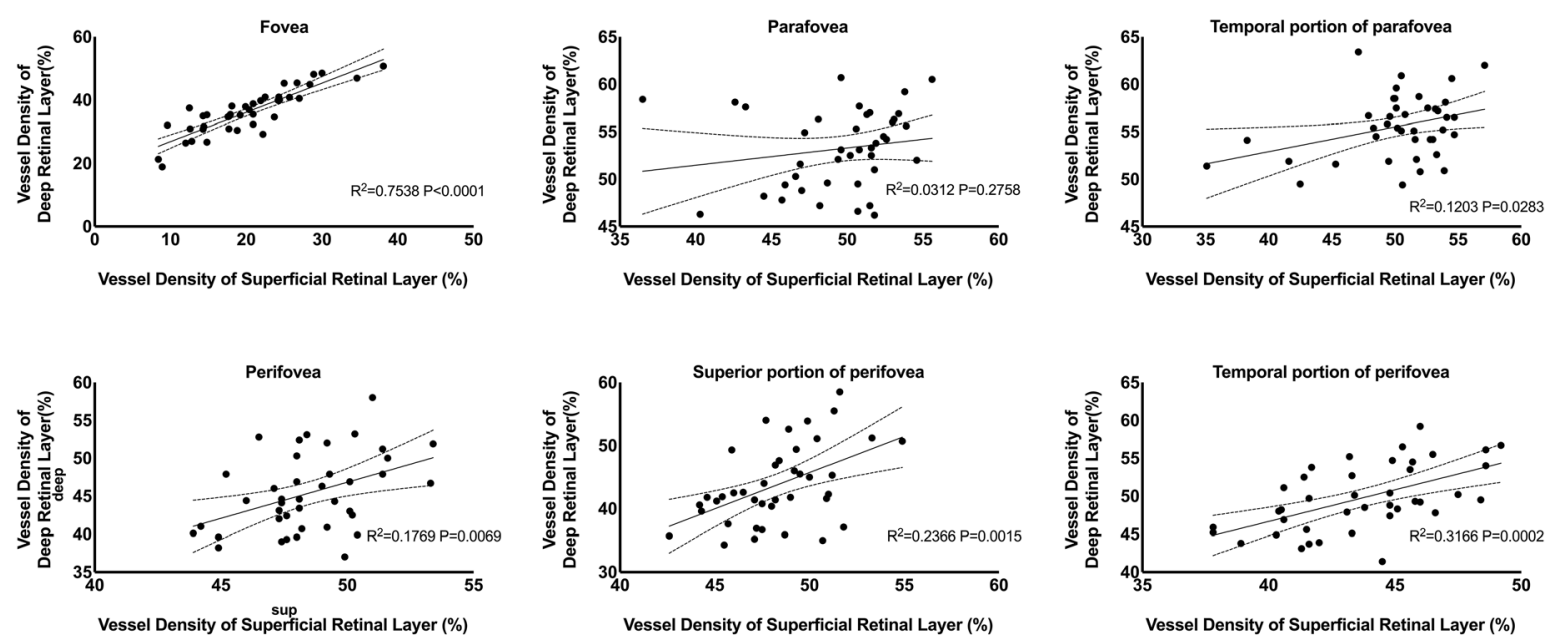

Fig. 2 Scatter plots and regression lines depicting the relationship between the superficial vessel density and deep vessel density at different retinal sectors in overall subjects at baseline

and temporal quadrant $(P=0.0015)$ of the perifoveal region (Fig. 2).
Besides, we investigated the local correlation between the RVD and RT of two layers. There 


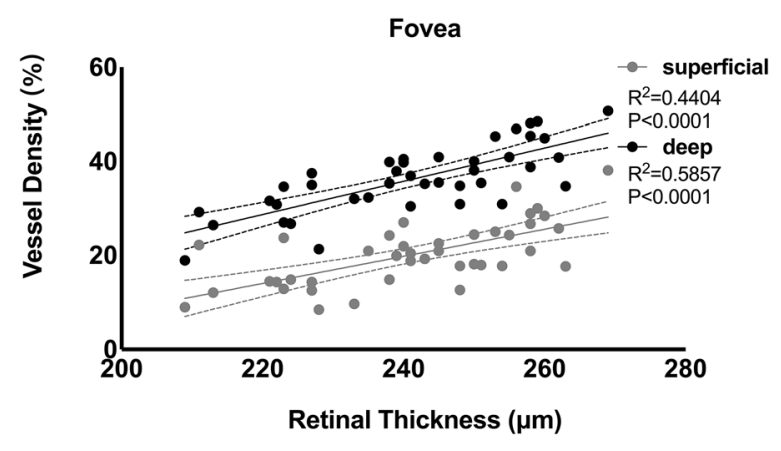

Fig. 3 Scatter plots and regression lines depicting the relationship between the retinal thickness in the foveal region and the superficial (gray dots and lines) and deep vessel density (black dots and lines), respectively, in overall subjects at baseline

was a significant positive correlation in the foveal region of two layers $(P<0.0001)$ and the nasal perifoveal subfield of SCP $(P=0.032)$ (Fig. 3).

SE and AL were significantly correlated with each other $(r=-0.571, P<0.001)$, while only AL showed correlation with whole, parafoveal and perifoveal sRVD. There was significant correlation between FAZ and vascular parametes of retina, such as foveal RT, foveal SRVD and foveal dRVD (Table 2).

\section{Changes in Spherical Equivalent, Axial Length and Other Ophthalmic Parameters}

A progression of myopia was observed in both group at the end of 3 months, with subjects in the control group showing a larger progression of SE than those in the atropine group $(-0.26 \pm 0.23$ vs. $-0.11 \pm 0.26 \mathrm{D}, P<0.05)$. Comparing with the atropine-treated eyes, the control eyes also showed a remarkable increase in $\mathrm{AL}$ after 3 months $(0.12 \pm 0.09$ vs. $0.04 \pm 0.12 \mathrm{~mm}, P<0.01)$. The mean changes in BCVA, other axial measurements (including ACD, CCT and LT) and keratometry values (including $\mathrm{K} 1, \mathrm{~K} 2$ and $\Delta \mathrm{K}$ ) were similar between the two groups at two follow-up visits.

\section{Changes in Structural and Vascular Parameters of the Choroid at Follow-Up Visits}

The mean of the difference in subfoveal ChT measurement between the two observers at three visits was $-0.7 \mu \mathrm{m}$ and with $95 \%$ limits of agreement was +27.6 to $-29.0 \mu \mathrm{m}$, indicating good intraobserver repeatability (Fig. 4). Subfoveal ChT in the atropine group was increased from $249.98 \pm 38.26 \mu \mathrm{m}$ at baseline to $261.10 \pm 43.25 \mu \mathrm{m}$ at 3 -month $(P<0.001)$, while ChT slightly increased from $229.78 \pm 46.73 \mu \mathrm{m} \quad$ to $\quad 235.31 \pm 46.43 \mu \mathrm{m}$ $(P=0.096)$ in the control group. However, there was no statistical difference in the mean change over time between two groups $(P=0.22)$ (Table 3). No significant difference was detected in CCF between two groups over 3 months.

In the atropine group, the thickening of the choroid was negatively correlated with the elongation of $\mathrm{AL}(r=-0.624, P=0.002)$ and positively correlated with the change of SE $(r=0.445, P=0.043)$, but not correlated with age, AL, SE or ChT at baseline (Table 4, Fig. 5).

\section{Changes in Structural and Vascular Parameters of the Retina at Follow-Up Visits}

In the atropine group, RT at all locations increased about $1 \mu \mathrm{m}$ from baseline to the 3 -month visit. However, none of the retinal subfields showed statistically significant difference in the mean changes of RT between the atropine group and the control group. Similarly, the change of RVD in neither SCP nor DCP showed significant difference between two groups. The FAZ of the treatment group was not affected by atropine use over time, and there was no difference between two groups (Table 3).

In atropine group, there was significant correlation between the elongation of $\mathrm{AL}$ and the changes of some structural parameters of the retina, such as whole RT, parafoveal RT and perifoveal RT $(P=0.002, P=0.021, P=0.004$, respectively) (Table 4 ), whereas in the control group, the elongation of AL was negatively correlated with the changes of other vascular 


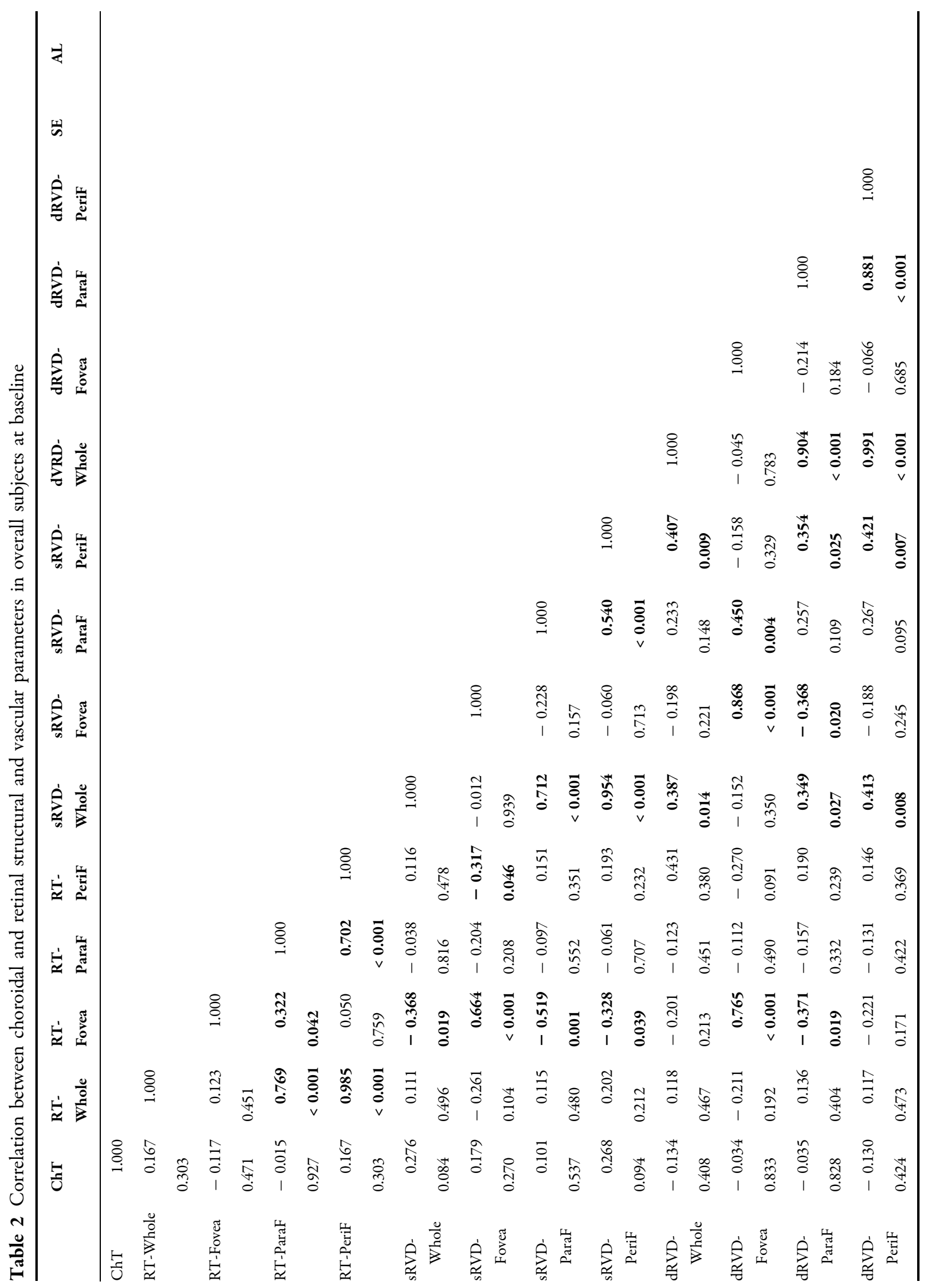




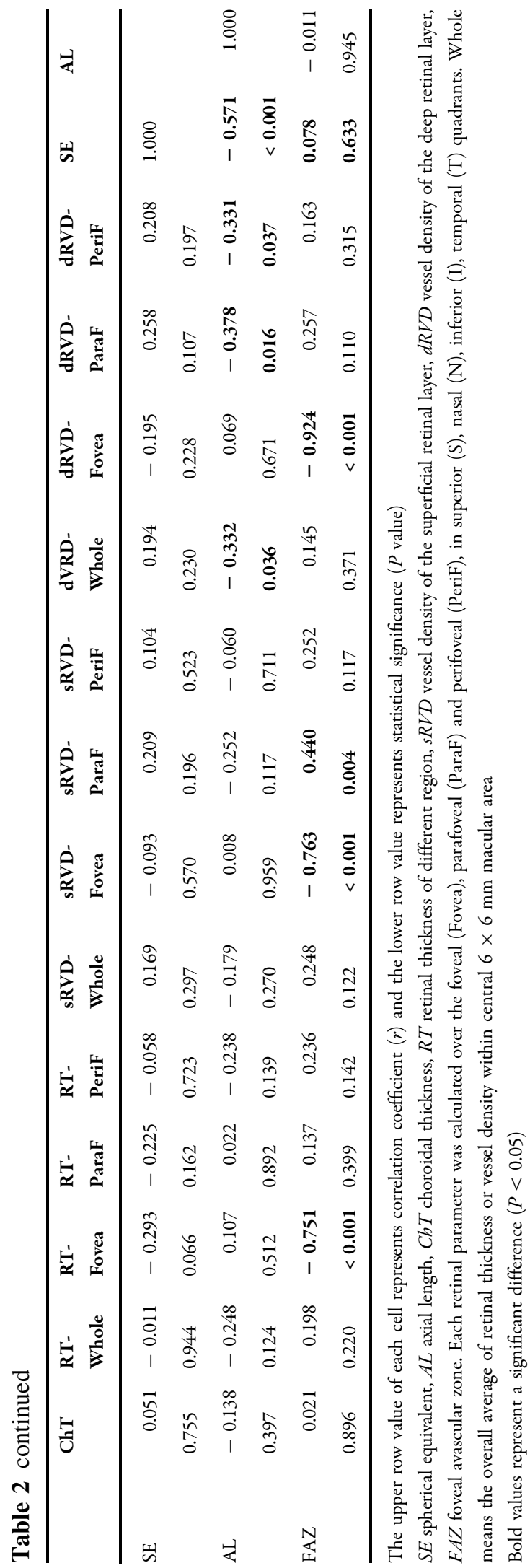

parameters of retina, such as whole dRVD, parafoveal dRVD and perifoveal dRVD $(P=0.029$, $P=0.028, P=0.027$, respectively) (Table S5).

\section{Prediction of Longitudinal Changes in Axial Length}

The multiple regression model included baseline age, change in ChT, change in RT and administration of atropine as independent variables to predict changes in $\mathrm{AL}$ over 3 months. According to the model, the thickening or less thinning of the subfoveal choroid and retina within central $6 \times 6 \mathrm{~mm}$ macular area, administration of atropine $0.01 \%$ eye drops and older age were associated with less elongation of AL (Table 5).

\section{DISCUSSION}

It is important to evaluate the impact of myopia upon the retinal and choroidal structure and vasculature in children, as myopia typically manifests and progresses in childhood. In this study, the distribution and association profiles of and the influence of atropine $0.01 \%$ eye drops on the retinal and choroidal structure and vasculature in myopic children were evaluated.

Evidence from both animal experiments and clinical studies suggested that the choroid was closely related with myopia. It was indicated that the thickness of the choroid changed rapidly to compensate for lens-induced myopic defocus $[22,23]$ and to response to form deprivation [24] in animal models. The ChT was dramatically thinner in highly myopic humans, which may be attributed to degenerative changes owing to long-term biomechanical stretching by excessive elongation of axial length $[25,26]$. Besides, the area of flow deficit in the choriocapillaris layer of myopic human eyes was increased [27], while the density and diameter of choriocapillaris were decreased in myopic chick eyes [28].

Notably, the choroidal thickness measured among different clinical studies exhibited discrepant results. In the present study, the ChT at baseline was relatively closer to the measurements of studies on Asian children [29, 30]. In 


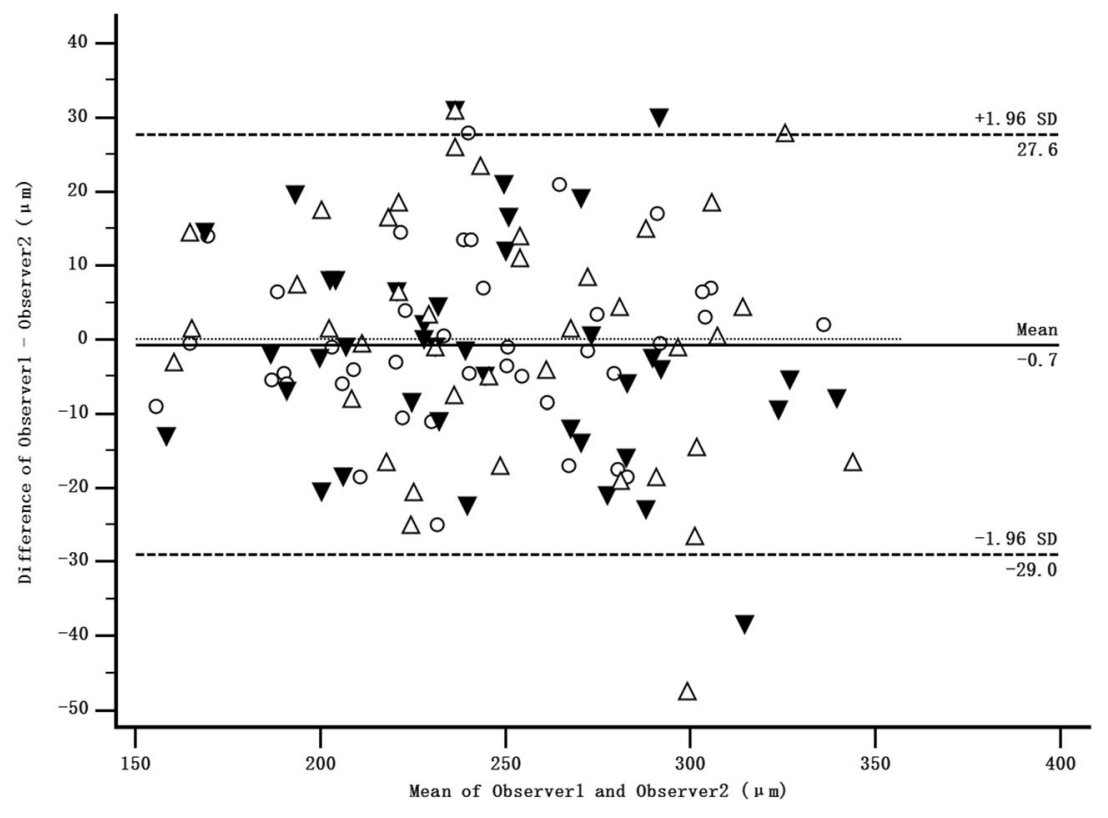

Fig. 4 Bland-Altman plot illustrating the repeatability of the ChT measurement between the two observers at baseline (circles), 1-month visit (black triangles) and 3 -month visit (white triangles). The mean of observer 1

addition, the trend of choroidal thinning with increasing age in this study was also consistent with several previous studies in Asian children $[31,32]$ instead of western children [33, 34]. Whether ethnic difference exists in the variation of ChT and whether this can partly explain myopia predisposition in Asian population warrant further study. Moreover, the large standard deviation of the ChT in this study and prior studies indicated the presence of considerable individual differences in the absolute thickness values.

The ChT tended to decrease with progression of myopia, which was consistent with earlier studies [29]. Notably, the measurement of thickness alone is not able to reflect thorough changes in the choroid during the progression of myopia. Gupta et al. reported that the choroidal thinning in highly myopic eyes might be associated with reduction in both vascular and stromal components [35]. However, the present study found no significant correlation between CCF and any of the parameters, which was consistent with the prior study [36]. and 2 was plotted against the difference between two observers (mean difference is shown with the solid line; 95\% limits of agreement are shown with the dashed lines)

In the present study, the range of RT within the ETDRS grids corroborated earlier studies, and the RT exhibited topographic variations among different regions and quadrants [29, 37]. Previous studies reported that RT was observed to increase with age $[38,39]$. Our study showed that baseline RT of three ETDRS areas and baseline overall average RT increased with age as well, although the difference was neither clinically nor statistically significant.

To date, the relationship between RT and progression of myopia in children remains elusive. Some studies demonstrated that foveal RT was significantly decreased in highly myopic subjects [40], and some studies found that increasing axial myopia was associated with increased foveal RT and reduced parafoveal and perifoveal RT [37], or quadrant-specific RT $[41,42]$, while others reported the absence of any association [43]. The current study found no significant correlation between baseline RT and baseline $\mathrm{AL}$ or $\mathrm{SE}$. The inconsistencies between different studies could be attributed to the differences in study designs, study cohorts and measurement approaches. 
Table 3 Mean changes in structural and vascular parameters of the choroid and retina parameters from baseline over 3 months

\begin{tabular}{|c|c|c|c|}
\hline & $\begin{array}{l}\text { Atropine group } \\
\text { Mean }(\mathrm{SD}), N=21\end{array}$ & $\begin{array}{l}\text { Control group } \\
\text { Mean (SD), } N=18\end{array}$ & $P$ value \\
\hline \multicolumn{4}{|l|}{ Spherical equivalent (D) } \\
\hline Mean change over 1 month & $-0.07(0.18)$ & $-0.13(0.21) \dagger$ & 0.43 \\
\hline Mean change over 3 months & $-0.11(0.26) \dagger$ & $-0.26(0.23) \dagger$ & $<0.05^{*}$ \\
\hline \multicolumn{4}{|l|}{ Axial length (mm) } \\
\hline Mean change over 1 month & $0.01(0.05)$ & $0.04(0.05)$ & 0.32 \\
\hline Mean change over 3 months & $0.04(0.12) \dagger$ & $0.12(0.09) \dagger$ & $<0.01^{*}$ \\
\hline \multicolumn{4}{|l|}{ BCVA (logMAR) } \\
\hline Mean change over 1 month & $-0.01(0.03) \dagger$ & $0.00(0.00)$ & 0.11 \\
\hline Mean change over 3 months & $-0.01(0.02)$ & $0.01(0.02)$ & 0.09 \\
\hline \multicolumn{4}{|l|}{ K1 (D) } \\
\hline Mean change over 1 month & $-0.02(0.13)$ & $-0.01(0.12)$ & 0.89 \\
\hline Mean change over 3 months & $0.00(0.13)$ & $-0.03(0.17)$ & 0.48 \\
\hline \multicolumn{4}{|l|}{ K2 (D) } \\
\hline Mean change over 1 month & $0.00(0.13)$ & $0.06(0.14)$ & 0.31 \\
\hline Mean change over 3 months & $0.02(0.15)$ & $0.07(0.23)$ & 0.38 \\
\hline \multicolumn{4}{|l|}{$\Delta \mathrm{K}(\mathrm{D})$} \\
\hline Mean change over 1 month & $-0.02(0.20)$ & $-0.07(0.18)$ & 0.42 \\
\hline Mean change over 3 months & $0.02(0.21)$ & $-0.09(0.22) \dagger$ & 0.23 \\
\hline \multicolumn{4}{|l|}{ ССТ $(\mu \mathrm{m})$} \\
\hline Mean change over 1 month & $-2.52(3.84) \dagger$ & $-1.33(6.93)$ & 0.49 \\
\hline Mean change over 3 months & $-1.81(4.60)$ & $-2.44(6.66)$ & 0.71 \\
\hline \multicolumn{4}{|l|}{$\mathrm{ACD}(\mathrm{mm})$} \\
\hline Mean change over 1 month & $0.01(0.03)$ & $0.01(0.05)$ & 0.84 \\
\hline Mean change over 3 months & $0.02(0.04) \dagger$ & $0.01(0.05)$ & 0.68 \\
\hline \multicolumn{4}{|l|}{$\mathrm{LT}(\mathrm{mm})$} \\
\hline Mean change over 1 month & $-0.00(0.03)$ & $-0.01(0.05)$ & 0.79 \\
\hline Mean change over 3 months & $-0.00(0.03)$ & $-0.01(0.06)$ & 0.62 \\
\hline \multicolumn{4}{|l|}{ Pupil (mm) } \\
\hline Mean change over 1 month & $1.20(0.63)^{\dagger}$ & $0.46(1.02)^{\dagger}$ & $0.02^{*}$ \\
\hline Mean change over 3 months & $1.00(1.08)^{\dagger}$ & $0.33(1.16)^{\dagger}$ & $0.05^{*}$ \\
\hline $\operatorname{ChT}(\mu \mathrm{m})$ & & & \\
\hline
\end{tabular}


Table 3 continued

\begin{tabular}{|c|c|c|c|}
\hline & $\begin{array}{l}\text { Atropine group } \\
\text { Mean }(S D), N=21\end{array}$ & $\begin{array}{l}\text { Control group } \\
\text { Mean }(\text { SD), } N=18\end{array}$ & $P$ value \\
\hline Mean change over 1 month & $5.20(10.86)$ & $3.88(8.86)$ & 0.77 \\
\hline Mean change over 3 months & $11.12(13.96) \dagger$ & $5.53(16.86)$ & 0.22 \\
\hline \multicolumn{4}{|l|}{$\mathrm{CCF}\left(\mathrm{mm}^{2}\right)$} \\
\hline Mean change over 1 month & $0.01(0.06)$ & $-0.14(0.08)$ & 0.43 \\
\hline Mean change over 3 months & $0.02(0.06)$ & $-0.01(0.10)$ & 0.26 \\
\hline \multicolumn{4}{|l|}{ RT-Whole $(\mu \mathrm{m})$} \\
\hline Mean change over 1 month & $1.00(2.51)$ & $0.61(1.69)$ & 0.63 \\
\hline Mean change over 3 months & $1.76(2.90) \dagger$ & $0.78(2.44)$ & 0.22 \\
\hline \multicolumn{4}{|l|}{ RT-Fovea $(\mu \mathrm{m})$} \\
\hline Mean change over 1 month & $0.29(2.03)$ & $0.44(2.43)$ & 0.83 \\
\hline Mean change over 3 months & $0.90(1.84)$ & $0.72(2.89)$ & 0.81 \\
\hline \multicolumn{4}{|l|}{ RT-ParaF $(\mu \mathrm{m})$} \\
\hline Mean change over 1 month & $0.76(2.66)$ & $0.44(2.59)$ & 0.71 \\
\hline Mean change over 3 months & $1.33(2.50) \dagger$ & $0.94(2.96)$ & 0.65 \\
\hline \multicolumn{4}{|l|}{ RT-ParaF-S $(\mu \mathrm{m})$} \\
\hline Mean change over 1 month & $0.86(2.61)$ & $0.72(2.80)$ & 0.89 \\
\hline Mean change over 3 months & $1.81(3.01) \dagger$ & $1.50(3.82) \dagger$ & 0.76 \\
\hline \multicolumn{4}{|l|}{ RT-ParaF-I $(\mu \mathrm{m})$} \\
\hline Mean change over 1 month & $1.10(2.61)$ & $-0.28(3.69)$ & 0.17 \\
\hline Mean change over 3 months & $1.71(2.74) \dagger$ & $0.50(4.08)$ & 0.22 \\
\hline \multicolumn{4}{|l|}{ RT-ParaF-N $(\mu \mathrm{m})$} \\
\hline Mean change over 1 month & $0.14(2.57)$ & $1.61(3.38) \dagger$ & 0.14 \\
\hline Mean change over 3 months & $0.86(2.03)$ & $1.67(3.77) \dagger$ & 0.42 \\
\hline \multicolumn{4}{|l|}{ RT-ParaF-T $(\mu \mathrm{m})$} \\
\hline Mean change over 1 month & $1.19(3.12)$ & $0.00(0.51)$ & 0.20 \\
\hline Mean change over 3 months & $1.48(2.84) \dagger$ & $0.11(3.22)$ & 0.14 \\
\hline \multicolumn{4}{|l|}{ RT-PeriF $(\mu \mathrm{m})$} \\
\hline Mean change over 1 month & $0.95(2.44)$ & $0.78(1.70)$ & 0.83 \\
\hline Mean change over 3 months & $1.67(2.56) \dagger$ & $1.28(2.67) \dagger$ & 0.63 \\
\hline \multicolumn{4}{|l|}{ RT-PeriF-S $(\mu \mathrm{m})$} \\
\hline Mean change over 1 month & $0.90(2.96)$ & $1.39(2.00) \dagger$ & 0.61 \\
\hline Mean change over 3 months & $1.81(2.52) \dagger$ & $1.83(3.03) \dagger$ & 0.98 \\
\hline
\end{tabular}


Table 3 continued

$\begin{array}{ll}\text { Atropine group } & \text { Control group } \\ \text { Mean (SD) }, N=21 & \text { Mean }(S D), N=18\end{array}$

$P$ value

Mean (SD), $N=21$

Mean (SD), $N=18$

RT-PeriF-I $(\mu \mathrm{m})$

Mean change over 1 month

Mean change over 3 months

RT-PeriF-N $(\mu \mathrm{m})$

Mean change over 1 month

Mean change over 3 months

RT-PeriF-T $(\mu \mathrm{m})$

Mean change over 1 month

Mean change over 3 months

sRVD-Whole (\%)

Mean change over 1 month

Mean change over 3 months

sRVD-Fovea (\%)

Mean change over 1 month

Mean change over 3 months

sRVD-ParaF (\%)

Mean change over 1 month

Mean change over 3 months

sRVD-ParaF-S (\%)

Mean change over 1 month

Mean change over 3 months

sRVD-ParaF-I (\%)

Mean change over 1 month

Mean change over 3 months

sRVD-ParaF-N (\%)

Mean change over 1 month

Mean change over 3 months

sRVD-ParaF-T (\%)

Mean change over 1 month

Mean change over 3 months

sRVD-PeriF (\%)

Mean change over 1 month
$1.48(2.14) \dagger$

$2.05(3.02) \dagger$

$0.90(2.91)$

$1.76(2.91) \dagger$

$0.90(3.10)$

$1.14(3.05)$

$0.54(2.11)$

$0.17(2.17)$

$0.99(2.29)$

$0.11(2.87)$

$0.94(2.24)$

1.15 (4.07)

0.87

$0.25(3.50)$

$1.11(5.54)$

0.50

$1.28(2.95)$

$1.63(5.15)$

0.80

0.50 (3.93)

1.66 (5.62)

0.40

1.61 (3.36)

0.99 (5.44)

0.66

$0.70(3.91)$

0.93 (5.59)

0.87

$0.62(3.52)$

$0.98(4.71)$

0.84

-0.04 (5.69)

$0.12(7.35)$

0.93

$0.31(2.09)$

$1.00(4.52)$

0.64

-0.09 (3.71)

1.68 (6.58)

0.22

$0.41(2.25)$ 
Table 3 continued

\begin{tabular}{|c|c|c|c|}
\hline & $\begin{array}{l}\text { Atropine group } \\
\text { Mean }(\mathrm{SD}), N=21\end{array}$ & $\begin{array}{l}\text { Control group } \\
\text { Mean }(\mathrm{SD}), N=18\end{array}$ & $P$ value \\
\hline Mean change over 3 months & $0.17(2.22)$ & $0.54(2.61)$ & 0.63 \\
\hline \multicolumn{4}{|l|}{ sRVD-PeriF-S (\%) } \\
\hline Mean change over 1 month & $0.77(2.47)$ & $1.26(2.75) \dagger$ & 0.56 \\
\hline Mean change over 3 months & $0.43(2.49)$ & $0.85(2.47)$ & 0.61 \\
\hline \multicolumn{4}{|l|}{ sRVD-PeriF-I (\%) } \\
\hline Mean change over 1 month & $0.27(2.41)$ & $0.68(2.55)$ & 0.61 \\
\hline Mean change over 3 months & $-0.16(2.61)$ & $-0.27(2.77)$ & 0.89 \\
\hline \multicolumn{4}{|l|}{ sRVD-PeriF-N (\%) } \\
\hline Mean change over 1 month & $-0.06(2.42)$ & $0.87(1.96)$ & 0.22 \\
\hline Mean change over 3 months & $-0.16(2.59)$ & $0.35(2.36)$ & 0.50 \\
\hline \multicolumn{4}{|l|}{ sRVD-PeriF-T (\%) } \\
\hline Mean change over 1 month & $0.72(2.85)$ & $0.54(3.33)$ & 0.86 \\
\hline Mean change over 3 months & $0.53(2.49)$ & $1.15(3.81)$ & 0.57 \\
\hline \multicolumn{4}{|l|}{ dRVD-Whole (\%) } \\
\hline Mean change over 1 month & $0.43(5.94)$ & $-1.89(5.25)$ & 0.19 \\
\hline Mean change over 3 months & $0.82(4.66)$ & $0.09(5.26)$ & 0.68 \\
\hline \multicolumn{4}{|l|}{ dRVD-Fovea (\%) } \\
\hline Mean change over 1 month & $-0.11(5.34)$ & $-0.43(2.78)$ & 0.80 \\
\hline Mean change over 3 months & $0.46(2.51)$ & $0.98(2.96)$ & 0.68 \\
\hline \multicolumn{4}{|l|}{ dRVD-ParaF (\%) } \\
\hline Mean change over 1 month & $-0.13(4.68)$ & $-1.87(4.89)$ & 0.24 \\
\hline Mean change over 3 months & $0.29(4.09)$ & $-0.25(4.25)$ & 0.72 \\
\hline \multicolumn{4}{|l|}{ dRVD-ParaF-S (\%) } \\
\hline Mean change over 1 month & $0.10(5.65)$ & $-1.61(7.30)$ & 0.40 \\
\hline Mean change over 3 months & $0.09(6.23)$ & $0.14(5.45)$ & 0.98 \\
\hline \multicolumn{4}{|l|}{ dRVD-ParaF-I (\%) } \\
\hline Mean change over 1 month & $-0.18(6.60)$ & $-0.38(5.56)$ & 0.92 \\
\hline Mean change over 3 months & $-0.27(5.03)$ & $0.81(6.82)$ & 0.58 \\
\hline \multicolumn{4}{|l|}{ dRVD-ParaF-N (\%) } \\
\hline Mean change over 1 month & $0.30(3.91)$ & $-2.37(6.35) \dagger$ & 0.08 \\
\hline Mean change over 3 months & $1.09(4.02)$ & $-1.34(4.53)$ & 0.11 \\
\hline dRVD-ParaF-T (\%) & & & \\
\hline
\end{tabular}


Table 3 continued

\begin{tabular}{|c|c|c|c|}
\hline & $\begin{array}{l}\text { Atropine group } \\
\text { Mean }(\mathrm{SD}), N=21\end{array}$ & $\begin{array}{l}\text { Control group } \\
\text { Mean }(S D), N=18\end{array}$ & $P$ value \\
\hline Mean change over 1 month & $-0.73(4.49)$ & $-3.12(4.34) \dagger$ & 0.09 \\
\hline Mean change over 3 months & $0.25(3.21)$ & $-0.61(4.18)$ & 0.55 \\
\hline \multicolumn{4}{|l|}{ dRVD-PeriF (\%) } \\
\hline Mean change over 1 month & $0.58(6.37)$ & $-1.91(5.80)$ & 0.21 \\
\hline Mean change over 3 months & $0.95(5.14)$ & $0.28(5.69)$ & 0.74 \\
\hline \multicolumn{4}{|l|}{ dRVD-PeriF-S (\%) } \\
\hline Mean change over 1 month & $0.95(7.23)$ & $-0.78(7.14)$ & 0.46 \\
\hline Mean change over 3 months & $1.00(6.84)$ & $1.12(6.06)$ & 0.96 \\
\hline \multicolumn{4}{|l|}{ dRVD-PeriF-I (\%) } \\
\hline Mean change over 1 month & $1.27(8.14)$ & $-3.02(7.09)$ & 0.07 \\
\hline Mean change over 3 months & $1.62(5.17)$ & $-0.93(7.57)$ & 0.28 \\
\hline \multicolumn{4}{|l|}{ dRVD-PeriF-N (\%) } \\
\hline Mean change over 1 month & $0.44(6.79)$ & $-2.24(5.69)$ & 0.19 \\
\hline Mean change over 3 months & $0.46(5.65)$ & $-0.19(5.93)$ & 0.75 \\
\hline \multicolumn{4}{|l|}{ dRVD-PeriF-T (\%) } \\
\hline Mean change over 1 month & $-0.39(5.39)$ & $-1.62(5.26)$ & 0.51 \\
\hline Mean change over 3 months & $0.57(4.49)$ & $1.04(5.93)$ & 0.80 \\
\hline \multicolumn{4}{|l|}{$\mathrm{FAZ}\left(\mathrm{mm}^{2}\right)$} \\
\hline Mean change over 1 month & $0.00(0.01)$ & $0.00(0.01)$ & 0.35 \\
\hline Mean change over 3 months & $0.00(0.01)$ & $-0.01(0.02)$ & 0.32 \\
\hline
\end{tabular}

$S E$ spherical equivalent, $A L$ axial length, $B C V A$ best corrected visual acuity, $K 1$ flat keratometry, $K 2$ steep keratometry, $\Delta K$ corneal astigmatism, $C C T$ central corneal thickness, $A C D$ anterior chamber depth, $L T$ lens thickness, $C h T$ choroidal thickness, $C C F$ choriocapillaris flow, RT-: retinal thickness of different region, sRVD-: vessel density of the superficial retinal layer, $d R V D$ vessel density of the deep retinal layer, $F A Z$ foveal avascular zone. The mean of each retinal parameter was calculated over the foveal (Fovea), parafoveal (ParaF) and perifoveal (PeriF), in superior (S), nasal (N), inferior (I), temporal $(\mathrm{T})$ quadrants. Whole means the overall average of retinal thickness or vessel density within central $6 \times 6 \mathrm{~mm}$ macular area

*Between-group significant differences at $P<0.05$

${ }^{\dagger}$ Within-group significant differences with baseline at $P<0.05$

Previous studies by various methods have revealed degenerated changes of retinal vessels in highly myopic eyes, including decreased blood flow, narrowed vessel diameter [44] and altered microvascular network [45, 46].
However, few previous publications studying retinal microcirculation in children are available. Two prior studies have observed that narrower retinal arteriolar and venular caliber was associated with longer AL in children $[47,48]$. 


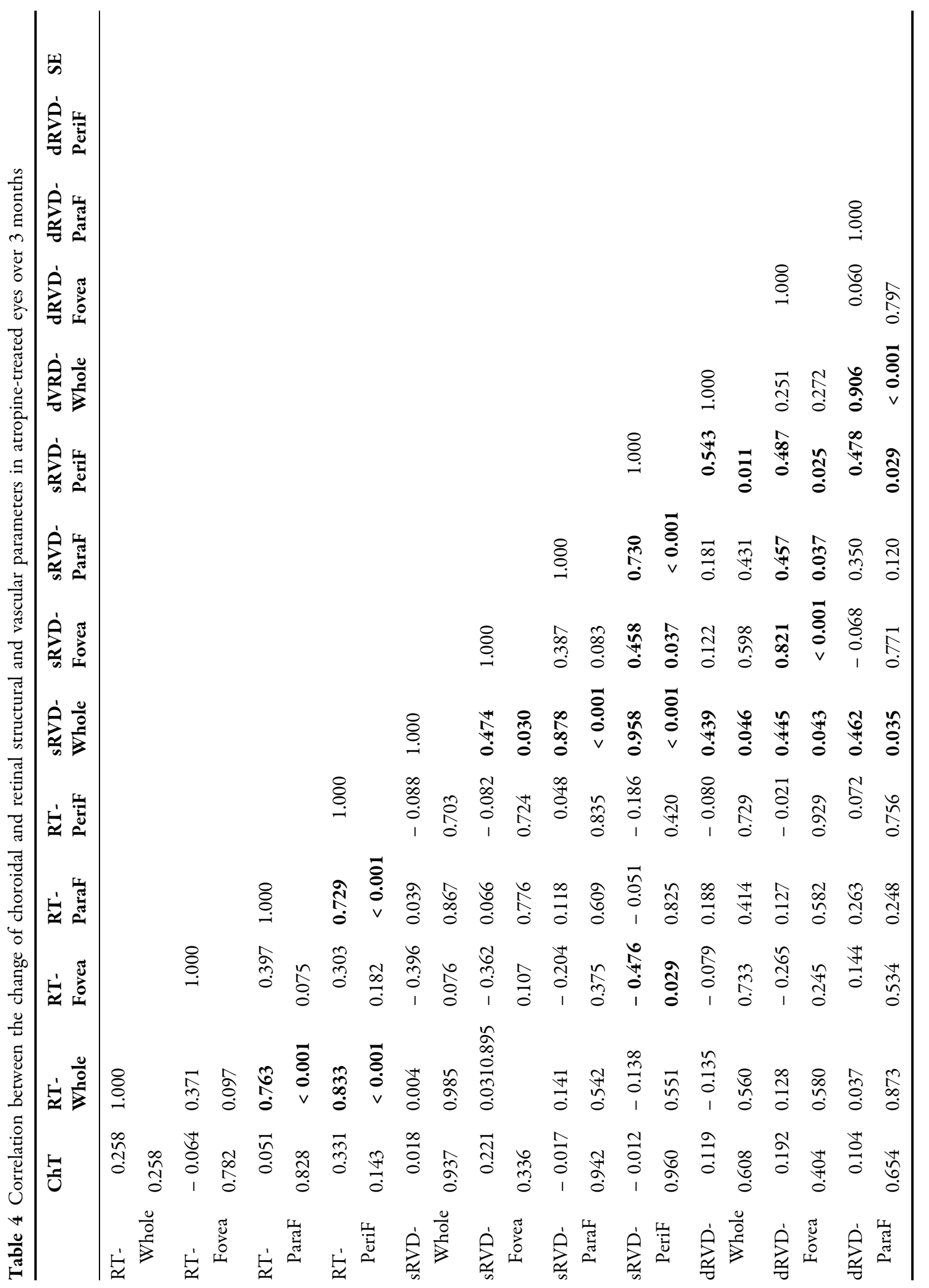




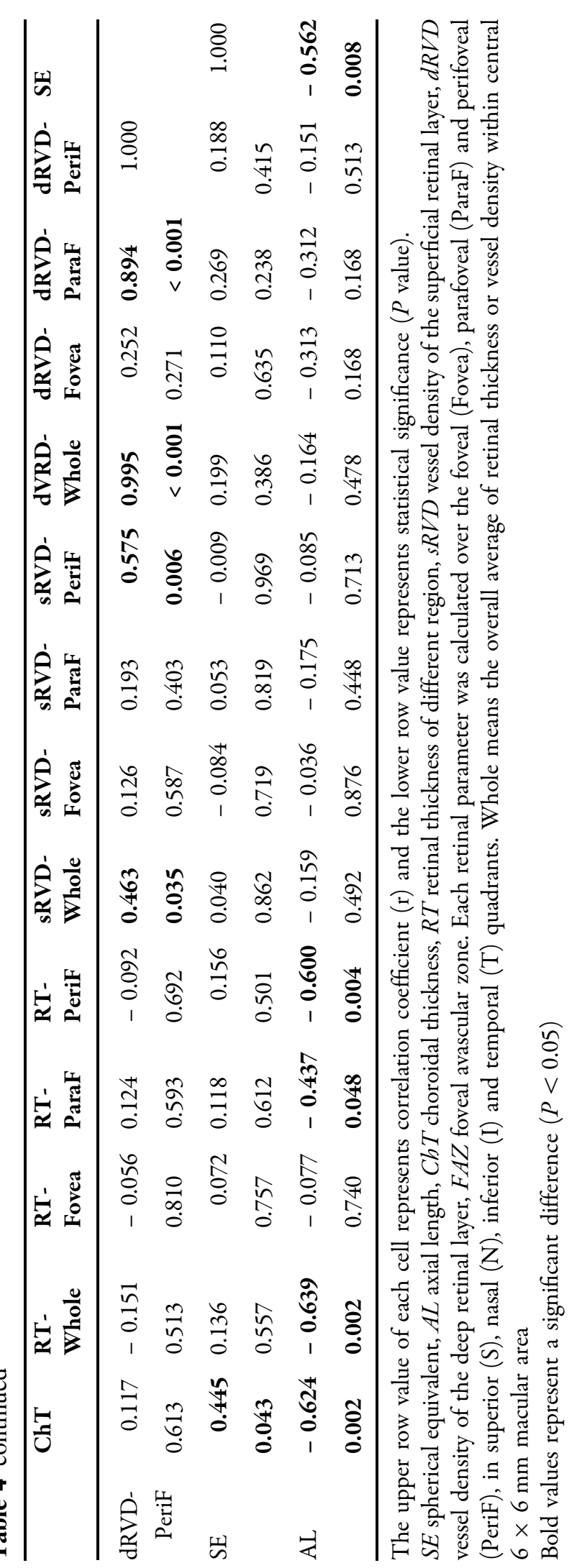




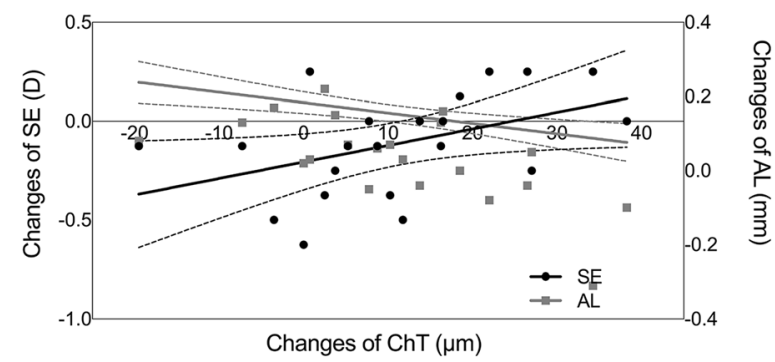

Fig. 5 Scatter plots and regression lines depicting the relationship between the change of subfoveal choroidal thickness and the change of spherical equivalent (black dots and lines) and the change of axial length (gray squares and lines), respectively, in atropine-treated subjects at 3-month visit

Another study found that foveal and parafoveal sRVD is decreased in myopic Caucasian children [49]. In the current study, the researchers found that baseline parafoveal dRVD, perifoveal dRVD and overall average dRVD were negatively correlated with baseline AL. Besides, there were no significant correlations between baseline dRVD values and SE. The results were partly in accordance with findings from Cheng and associates, which demonstrated perifoveal dRVD was most associated with retinal capillary loss related to myopia [50]. Note that the effect of image magnification on OCTA-derived variables such as sRVD could result in about 5\% difference in eyes with $\mathrm{AL}$ in the range from 22.28 to $24.33 \mathrm{~mm}$ [51]. Thus, the comparison of our results with aforementioned studies should be interpreted with caution because of the discrepancies in segmentation of the retinal layers and the refractive status or axial length of the study population.

In terms of topographical variation of $\mathrm{VD}$ at different retinal locations, the SRVD was significantly positively correlated with dRVD in all three EDTRS regions.Other than that, a regular pattern of RVD among different quadrants does not exist. Milani et al. found positive correlation between RT and SRVD in every portion of the macular area, especially in the fovea [52]. In contrast, we only observed positive correlation in the foveal region of two layers and the nasal perifoveal subfield of SCP. Further investigations are needed to confirm this finding and explore underlying mechanisms.

In term of the association between FAZ and myopia, one prior study demonstrated that the FAZ area was significantly larger in myopic than non-myopic children $\left(0.258 \mathrm{~mm}^{2}\right.$ vs. 0.224 $\mathrm{mm}^{2}, P=0.010$ ) [49]. Another study found a significant yet weak positive correlation between FAZ and vessel density in the superficial plexus [53]. In this study, baseline FAZ was not correlated with baseline SE or AL, whereas significant negative correlation was observed between FAZ and foveal RT, foveal SRVD, parafoveal sRVD and foveal dRVD.

Nickla et al. found that intravitreal injection of atropine caused rapid increases in ChT and

Table 5 Multiple regression analysis for predicting elongation of AL over 3 months

\begin{tabular}{|c|c|c|c|c|}
\hline & $\begin{array}{l}\text { Unstandardized } \\
\text { Coefficients } \\
B \text { (SE) }\end{array}$ & $\begin{array}{l}\text { Standardized } \\
\text { Coefficients } \\
\beta\end{array}$ & $t$ & $P$ value \\
\hline Administration of atropine & $-0.052(0.020)$ & -0.230 & -2.536 & 0.016 \\
\hline Age at baseline & $-0.026(0.006)$ & -0.402 & -4.538 & $<0.001$ \\
\hline Change of ChT & $-0.003(0.001)$ & -0.363 & -3.760 & 0.001 \\
\hline Change of RT-Whole & $-0.018(0.004)$ & -0.440 & -4.559 & $<0.001$ \\
\hline Intercept & $0.405(0.058)$ & & 6.957 & $<0.001$ \\
\hline
\end{tabular}

The coefficient of determination $\left(R^{2}\right)$ was 0.734

$C h T$ choroidal thickness, and $R T$-Whole means the overall average of retinal thickness 
inhibited the elongation of AL in myopic chick eyes [54]. The effects of topical administration of atropine on ChT in human were also evaluated by several clinical studies. One drop of $1 \%$ atropine gel administered twice daily for a week significantly thickened the choroid under the fovea by $15.48 \pm 16.13 \mu \mathrm{m}$ [55]. One drop of atropine $0.5 \%$ had no significant effect on ChT $22 \mathrm{~h}$ after instillation, but abolished a thinning response of the choroid to $2.00 \mathrm{D}$ of hyperopic retinal defocus [56]. Jiang and colleagues observed that the ChT in myopic eyes increased from $279.91 \pm 47.15$ to $306.80 \pm 44.97 \mu \mathrm{m}$ after administration of $1 \%$ atropine for 1 week and gradually returned to baseline levels 7 weeks after the withdrawal [57]. As for low concentration of atropine, two studies reported by Sander indicated that atropine $0.01 \%$ could also induce a slight thickening of the choroid in myopic adults and inhibit the thinning of the choroid caused by hyperopic blur $[58,59]$. Zhao et al. found that monotherapy with atropine $0.01 \%$ for 1 month induced significant thickening of the choroid $(5.49 \pm 9.38 \mu \mathrm{m})$ compared with the single-vision glasses group $(-4.81 \pm 9.93 \mu \mathrm{m})$, although the combination treatment with both orthokeratology and atropine resulted in a lager increase in ChT $(14.12 \pm 12.88 \mu \mathrm{m})$ [60]. One recent clinical trial also found that the increase in ChT was most in the combination group $(24.14 \pm 1.93 \mu \mathrm{m})$, followed by the orthokeratology group $(19.33 \pm 2.63 \mu \mathrm{m})$ and then atropine group $(8.09 \pm 1.47 \mu \mathrm{m})$ after 12 months [61].

The thickening response of the choroid was rapid and significant within only 1 month or even 1 week of atropine treatment $(1 \%, 0.3 \%$ and $0.01 \%$ atropine) and became slower and insignificant after that [61-63]. In the present study, the thickening of subfoveal ChT in the atropine group was $5.20 \pm 10.86 \mu \mathrm{m}$ at 1-month visit, which is comparable to the aforementioned study. The ChT continued to increase over 3 months $(11.12 \pm 13.96 \mu \mathrm{m})$, although the between-group difference was not significant compared with the control group. Notably, the degree of choroidal thickening was not as significant as envisioned compared with a mean amplitude of $33.7 \mu \mathrm{m}$ in diurnal ChT variation in healthy adults [64].

Results on the underlying mechanism of choroidal thickening during atropine treatment is so far inconclusive. On the one hand, atropine might affect choroidal thickness via antagonism of muscarinic receptors, such as acting on choroidal perivascular plexus or nonvascular smooth muscle cells, which could directly influence choroidal thickness, or changing contractile force of ciliary muscle, which might transmitted backward to the choroid and indirectly change its thickness. On the other hand, atropine might affect choroidal thickness in a muscarinic receptor-independent manner. For instance, atropine could mediate myopia inhibition by exhibiting off-target effect at other receptors such as $\alpha 2 \mathrm{~A}$-adrenergic receptor [65] or inducing the synthesis and release of neurotransmitters like dopamine or nitric oxide $[66,67]$. However, the muscarinic manner of action appears to be more likely, since significant increase in ChT was found after administration of other anti-muscarinic agents, such as cyclopentolate and homatropine [68, 69], whereas opposite change in ChT was observed after instillation of pilocarpine, a classic muscarinic agonist [70].

Zhou et al. observed that peribulbar injection of atropine inhibited form-deprivation myopia and attenuated the thinning of the choroid and reduction of choroidal blood perfusion [71]. Our study revealed that CCF remained stable regardless of the treatment or observation time, indicating that the choroidal capillary layer was not affected by atropine $0.01 \%$. Given a recently proposed hypothesis that altered choroidal vasculature and decreased choroidal blood flow may lead to scleral hypoxia which then triggers scleral remodeling and myopia development [72], more evidence is required to investigate the changes in choroidal structure and function and its relationship with myopia onset and progression [73].

Recent works by Khanal proposed that atropine $0.1 \%$ could affect neural activity in the inner retina, which suggested a potential involvement of multiple retinal neural cells in mediating the anti-myopia effects of atropine $[74,75]$. To date, there has been no detailed 
investigation of the effect of atropine $0.01 \%$ eye drops on the structure and vasculature of the retina in vivo in human. In this study, the changes of all structural and vascular parameters of the retina showed no significant difference between the atropine group and the control group, which indicated the short-term safety of atropine $0.01 \%$.

Except for assessing the effect of atropine $0.01 \%$ on structural and vascular parameters of the choroid and retina, another purpose of the study was to identify the risk factors and protective factors for childhood myopia. Given that myopia-related complications are primarily attributed to excessive elongation of the eye globe, we focused on finding predictive factors of axial elongation instead of the refraction change. In the current study, the elongation of $\mathrm{AL}$ is negatively correlated with the thinning of subfoveal ChT, whole RT, parafoveal RT and perifoveal RT. As the change of whole average RT was closely related with the changes of parafoveal and perifoveal RT, only the former one was included into the regression model. By adding the age at baseline and the administration of atropine $0.01 \%$ eye drops as two independent variables into the multiple regression analysis, we concluded that less elongation of $\mathrm{AL}$ was associated with less thinning of the subfoveal choroid and retina within central $6 \times 6 \mathrm{~mm}$ macular area, atropine treatment and an older age in myopic Chinese children.

Prospective longitudinal investigations might provide greater insights into the potential roles for the choroid and the retina in the development of childhood myopia. A previous 1-year longitudinal study found that the changes in the AL were significantly negatively correlated with changes in the ChT, changes in the SE, baseline AL and baseline SE [76]. One longitudinal assessment of retinal structure over 18 months indicated high stability of the macular retinal thickness in both myopic and nonmyopic adolescence in contrast to the significant increases in AL and ChT [77]. Another longitudinal study demonstrated that during pediatric myopic shift, ChT decreased in all regions, while most subfields of the retina thickened or were unchanged, with only the inferior perifoveal RT decreasing with SE [78].
In summary, our current study provided detailed assessment of short-term effects of atropine $0.01 \%$ on choroidal and retinal structure and vasculature over 3 months and presented an effective multivariable prediction model for axial length elongation, which incorporated both myopia-related clinical features and demographic information.

Our study had a few limitations. First, it is a single-center study, and the relatively small sample size might limit the ability to reach definitive conclusions. Second, the follow-up period of 3 months is relatively short, and longterm observations are required to expand the knowledge about the effects of atropine $0.01 \%$ on choroidal and retinal parameters. Third, the performance of the prediction model in predicting axial elongation needs to be verified in some validation cohorts in the future.

\section{CONCLUSIONS}

In conclusion, administration of atropine $0.01 \%$ eye drops demonstrated no significant short-term effect on choriocapillaris flow, the thickness and vessel density of the retina and foveal avascular zone. A modest increase of subfoveal choroidal thickness in the atropinetreated eyes at 3-month visit was observed; thus, a long-term follow-up is required to validate this effect. Combined with its reduction in spherical equivalent progression and axial elongation, atropine $0.01 \%$ could be used as an effective and safe treatment for myopia.

\section{ACKNOWLEDGEMENTS}

The authors are grateful to the children and their parents or guardians who participated in the study.

Funding. This study and publication of this article, including the journal's Rapid Service Fees, was supported by National Natural Science Foundation of China (grant no. 82171093) and Shanghai Scientific Research Plan Project (grant no. 21dz2311300). 
Authorship. All named authors meet the International Committee of Medical Journal Editors (ICMJE) criteria for authorship for this article, take responsibility for the integrity of the work as a whole, and have given their approval for this version to be published.

Author Contributions. Yuliang Wang made leading contributions to the acquisition, analysis and interpretation of data. Xingxue Zhu made supporting contributions to the acquisition, analysis and interpretation of data. Yi Xuan made leading contributions to the provision of the equipment and software used in the work. Min Wang made supporting contributions to the provision of the equipment and software used in the work. Xingtao Zhou made supporting contributions to the conception and design of the work. Xiaomei Qu made leading contributions to the conception and design of the work. All authors read and approved the final manuscript.

Disclosures. The authors have no conflicts of interest to declare that are relevant to the content of this article.

Compliance with Ethics Guidelines. This study was approved by the Ethics Committee of the Eye \& ENT Hospital of Fudan University (no. 2019022-1) and conducted in accordance with the tenets of the Declaration of Helsinki. Written informed consent was obtained from the parents or legal guardians of all enrollees, and either written or verbal consent was obtained from each participant.

Data Availability. The datasets generated during and/or analyzed during the current study are available from the corresponding author on reasonable request.

Open Access. This article is licensed under a Creative Commons Attribution-NonCommercial 4.0 International License, which permits any non-commercial use, sharing, adaptation, distribution and reproduction in any medium or format, as long as you give appropriate credit to the original author(s) and the source, provide a link to the Creative Commons licence, and indicate if changes were made. The images or other third party material in this article are included in the article's Creative Commons licence, unless indicated otherwise in a credit line to the material. If material is not included in the article's Creative Commons licence and your intended use is not permitted by statutory regulation or exceeds the permitted use, you will need to obtain permission directly from the copyright holder. To view a copy of this licence, visit http://creativecommons.org/licenses/by$\mathrm{nc} / 4.0 /$.

\section{REFERENCES}

1. Morgan IG, French AN, Ashby RS, Guo X, Ding X, $\mathrm{He} \mathrm{M}$, et al. The epidemics of myopia: aetiology and prevention. Prog Retin Eye Res. 2018;62:134-49.

2. Saw S-M, Gazzard G, Shih-Yen EC, Chua W-H. Myopia and associated pathological complications. Ophthalmic Physiol Opt. 2005;25(5):381-91.

3. Fricke TR, Holden BA, Wilson DA, Schlenther G, Naidoo KS, Resnikoff S, et al. Global cost of correcting vision impairment from uncorrected refractive error. Bull World Health Organ. 2012;90(10):728-38.

4. Walline JJ, Lindsley K, Vedula SS, Cotter SA, Mutti $\mathrm{DO}$, Twelker JD. Interventions to slow progression of myopia in children. Cochrane Database Syste Rev. 2011;12:CD004916.

5. Shih YF, Chen CH, Chou AC, Ho TC, Lin LL, Hung PT. Effects of different concentrations of atropine on controlling myopia in myopic children. J Ocul Pharmacol Ther. 1999;15(1):85-90.

6. Chia A, Chua WH, Wen L, Fong A, Goon YY, Tan D. Atropine for the treatment of childhood myopia: changes after stopping atropine $0.01 \%, 0.1 \%$ and 0 . 5\%. Am J Ophthalmol. 2014;157(2):451-7.e1.

7. Yam JC, Jiang Y, Tang SM, Law AKP, Chan JJ, Wong $\mathrm{E}$, et al. Low-concentration atropine for myopia progression (LAMP) study: a randomized, doubleblinded, placebo-controlled trial of $0.05 \%, 0.025 \%$, and $0.01 \%$ atropine eye drops in myopia control. Ophthalmology. 2019;126(1):113-24.

8. Wei S, Li SM, An W, Du J, Liang X, Sun Y, et al. Safety and efficacy of low-dose atropine eyedrops for the treatment of myopia progression in chinese children: a randomized clinical trial. JAMA Ophthalmol. 2020;138(11):1178-84. 
9. Fu A, Stapleton F, Wei L, Wang W, Zhao B, Watt K, et al. Effect of low-dose atropine on myopia progression, pupil diameter and accommodative amplitude: low-dose atropine and myopia progression. Br J Ophthalmol. 2020;104(11):1535-41.

10. Brennan NA, Toubouti YM, Cheng X, Bullimore MA. Efficacy in myopia control. Prog Retin Eye Res. 2021;83:100923.

11. Azuara-Blanco A, Logan N, Strang N, Saunders K, Allen PM, Weir R, et al. Low-dose (0.01\%) atropine eye-drops to reduce progression of myopia in children: a multicentre placebo-controlled randomised trial in the UK (CHAMP-UK)-study protocol. Br J Ophthalmol. 2020;104(7):950-5.

12. Hieda $\mathrm{O}$, Hiraoka T, Fujikado T, Ishiko $\mathrm{S}$, Hasebe $\mathrm{S}$, Torii $\mathrm{H}$, et al. Efficacy and safety of $0.01 \%$ atropine for prevention of childhood myopia in a 2-year randomized placebo-controlled study. Jpn J Ophthalmol. 2021;65(3):315-25.

13. Joachimsen L, Böhringer D, Gross NJ, Reich M, Stifter J, Reinhard T, et al. A pilot study on the efficacy and safety of $0.01 \%$ atropine in german schoolchildren with progressive myopia. Ophthalmol Ther. 2019;8(3):427-33.

14. Lee SSY, Mackey DA, Lingham G, Crewe JM, Richards MD, Chen FK, et al. Western Australia Atropine for the Treatment of Myopia (WA-ATOM) study: rationale, methodology and participant baseline characteristics. Clin Exp Ophthalmol. 2020;48(5):569-79.

15. McCrann S, Flitcroft I, Strang NC, Saunders KJ, Logan NS, Lee SS, et al. Myopia Outcome Study of Atropine in Children (MOSAIC): an investigatorled, double-masked, placebo-controlled, randomised clinical trial protocol. HRB Open Res. 2019;2:15.

16. Saxena R, Dhiman R, Gupta V, Kumar P, Matalia J, Roy L, et al. Atropine for the treatment of childhood myopia in India: multicentric randomized trial. Ophthalmology. 2021;128(9):1367-9.

17. Nickla DL, Wallman J. The multifunctional choroid. Prog Retin Eye Res. 2010;29(2):144-68.

18. Tkatchenko TV, Tkatchenko AV. Pharmacogenomic approach to antimyopia drug development: pathways lead the way. Trends Pharmacol Sci. 2019;40(11):833-52.

19. Jia Y, Tan O, Tokayer J, Potsaid B, Wang Y, Liu JJ, et al. Split-spectrum amplitude-decorrelation angiography with optical coherence tomography. Opt Express. 2012;20(4):4710-25.
20. Wang Y, Yao J, Qu X. Atropine 01\% for the control of myopia in chinese children: effect on accommodation functions and pupil size. J Ophthalmol. 2020;2020:7525180.

21. Bland JM, Altman DG. Measuring agreement in method comparison studies. Stat Methods Med Res. 1999;8(2):135-60.

22. Howlett $\mathrm{MH}$, McFadden SA. Spectacle lens compensation in the pigmented guinea pig. Vis Res. 2009;49(2):219-27.

23. Wildsoet C, Wallman J. Choroidal and scleral mechanisms of compensation for spectacle lenses in chicks. Vis Res. 1995;35(9):1175-94.

24. Hung LF, Wallman J, Smith EL 3rd. Vision-dependent changes in the choroidal thickness of macaque monkeys. Invest Ophthalmol Vis Sci. 2000;41(6): 1259-69.

25. Read SA, Fuss JA, Vincent SJ, Collins MJ, AlonsoCaneiro D. Choroidal changes in human myopia: insights from optical coherence tomography imaging. Clin Exp Optom. 2019;102(3):270-85.

26. Wang S, Wang Y, Gao X, Qian N, Zhuo Y. Choroidal thickness and high myopia: a cross-sectional study and meta-analysis. BMC Ophthalmol. 2015;15:70.

27. Al-Sheikh M, Phasukkijwatana N, Dolz-Marco R, Rahimi M, Iafe NA, Freund KB, et al. Quantitative OCT angiography of the retinal microvasculature and the choriocapillaris in myopic eyes. Invest Ophthalmol Vis Sci. 2017;58(4):2063-9.

28. Hirata A, Negi A. Morphological changes of choriocapillaris in experimentally induced chick myopia. Graefes Arch Clin Exp Ophthalmol. 1998;236(2):132-7.

29. Jin $\mathrm{P}$, Zou $\mathrm{H}, \mathrm{Zhu} \mathrm{J}, \mathrm{Xu} \mathrm{X}$, Jin J, Chang TC, et al. Choroidal and retinal thickness in children with different refractive status measured by swept-source optical coherence tomography. Am J Ophthalmol. 2016;168:164-76.

30. Deng J, Li X, Jin J, Zhang B, Zhu J, Zou H, et al. Distribution pattern of choroidal thickness at the posterior pole in chinese children with myopia. Invest Ophthalmol Vis Sci. 2018;59(3):1577-86.

31. He X, Jin P, Zou H, Li Q, Jin J, Lu L, et al. Choroidal thickness in healthy chinese children aged 6 to 12 : the Shanghai children eye study. Retina. 2017;37(2):368-75.

32. Nagasawa T, Mitamura Y, Katome T, Shinomiya K, Naito T, Nagasato D, et al. Macular choroidal thickness and volume in healthy pediatric 
individuals measured by swept-source optical coherence tomography. Invest Ophthalmol Vis Sci. 2013;54(10):7068-74.

33. Bidaut-Garnier M, Schwartz C, Puyraveau M, Montard M, Delbosc B, Saleh M. Choroidal thickness measurement in children using optical coherence tomography. Retina. 2014;34(4):768-74.

34. Read SA, Collins MJ, Vincent SJ, Alonso-Caneiro D. Choroidal thickness in childhood. Invest Ophthalmol Vis Sci. 2013;54(5):3586-93.

35. Gupta P, Thakku SG, Saw SM, Tan M, Lim E, Tan M, et al. Characterization of choroidal morphologic and vascular features in young men with high myopia using spectral-domain optical coherence tomography. Am J Ophthalmol. 2017;177:27-33.

36. Scherm P, Pettenkofer M, Maier M, Lohmann CP, Feucht N. Choriocapillary blood flow in myopic subjects measured with OCT angiography. Ophthalmic Surg Lasers Imaging Retina. 2019;50(5): e133-9.

37. Chen S, Wang B, Dong N, Ren X, Zhang T, Xiao L. Macular measurements using spectral-domain optical coherence tomography in Chinese myopic children. Invest Ophthalmol Vis Sci. 2014;55(11): 7410-6.

38. Matalia J, Anegondi NS, Veeboy L, Roy AS. Age and myopia associated optical coherence tomography of retina and choroid in pediatric eyes. Indian $\mathrm{J}$ Ophthalmol. 2018;66(1):77-82.

39. Read SA, Collins MJ, Vincent SJ, Alonso-Caneiro D. Macular retinal layer thickness in childhood. Retina. 2015;35(6):1223-33.

40. Lim HT, Chun BY. Comparison of OCT measurements between high myopic and low myopic children. Optom Vis Sci. 2013;90(12):1473-8.

41. Luo HD, Gazzard G, Fong A, Aung T, Hoh ST, Loon $\mathrm{SC}$, et al. Myopia, axial length, and OCT characteristics of the macula in Singaporean children. Invest Ophthalmol Vis Sci. 2006;47(7):2773-81.

42. Ziylan S, Kiziloglu OY, Yenerel NM, Gokce B, Ciftci F. Macular thickness in highly myopic children aged 3 to 7 years. J Pediatr Ophthalmol Strabismus. 2015;52(5):282-6.

43. Barrio-Barrio J, Noval S, Galdós M, Ruiz-Canela M, Bonet E, Capote M, et al. Multicenter Spanish study of spectral-domain optical coherence tomography in normal children. Acta Ophthalmol. 2013;91(1): e56-63.

44. Shimada N, Ohno-Matsui K, Harino S, Yoshida T, Yasuzumi K, Kojima A, et al. Reduction of retinal blood flow in high myopia. Graefes Arch Clin Exp Ophthalmol. 2004;242(4):284-8.

45. Li M, Yang Y, Jiang H, Gregori G, Roisman L, Zheng $\mathrm{F}$, et al. Retinal microvascular network and microcirculation assessments in high myopia. Am J Ophthalmol. 2017;174:56-67.

46. Yang Y, Wang J, Jiang H, Yang X, Feng L, Hu L, et al. Retinal microvasculature alteration in high myopia. Invest Ophthalmol Vis Sci. 2016;57(14):6020-30.

47. Li LJ, Cheung CY, Gazzard G, Chang L, Mitchell P, Wong TY, et al. Relationship of ocular biometry and retinal vascular caliber in preschoolers. Invest Ophthalmol Vis Sci. 2011;52(13):9561-6.

48. Cheung N, Tikellis G, Saw SM, Amirul Islam FM, Mitchell P, Wang JJ, et al. Relationship of axial length and retinal vascular caliber in children. Am J Ophthalmol. 2007;144(5):658-62.

49. Gołębiewska J, Biała-Gosek K, Czeszyk A, Hautz W. Optical coherence tomography angiography of superficial retinal vessel density and foveal avascular zone in myopic children. PLoS ONE. 2019;14(7): e0219785.

50. Cheng D, Chen Q, Wu Y, Yu X, Shen M, Zhuang X, et al. Deep perifoveal vessel density as an indicator of capillary loss in high myopia. Eye (Lond). 2019;33(12):1961-8.

51. Sampson DM, Gong P, An D, Menghini M, Hansen A, Mackey DA, et al. Axial length variation impacts on superficial retinal vessel density and foveal avascular zone area measurements using optical coherence tomography angiography. Invest Ophthalmol Vis Sci. 2017;58(7):3065-72.

52. Milani P, Montesano G, Rossetti L, Bergamini F, Pece A. Vessel density, retinal thickness, and choriocapillaris vascular flow in myopic eyes on OCT angiography. Graefes Arch Clin Exp Ophthalmol. 2018;256(8):1419-27.

53. Wylęgała A, Wang L, Zhang S, Liu Z, Teper S, Wylegała E. Comparison of foveal avascular zone and retinal vascular density in healthy Chinese and Caucasian adults. Acta Ophthalmol. 2020;98(4): e464-9.

54. Nickla DL, Zhu X, Wallman J. Effects of muscarinic agents on chick choroids in intact eyes and eyecups: evidence for a muscarinic mechanism in choroidal thinning. Ophthalmic Physiol Opt. 2013;33(3):245-56.

55. Zhang Z, Zhou Y, Xie Z, Chen T, Gu Y, Lu S, et al. The effect of topical atropine on the choroidal thickness of healthy children. Sci Rep. 2016;6: 34936. 
56. Chiang ST, Phillips JR. Effect of atropine eye drops on choroidal thinning induced by hyperopic retinal defocus. J Ophthalmol. 2018;2018:8528315.

57. Jiang Y, Zhang Z, Wu Z, Sun S, Fu Y, Ke B. Change and recovery of choroid thickness after short-term application of $1 \%$ atropine gel and its influencing factors in 6-7-year-old children. Curr Eye Res. 2021;46:1171-7.

58. Sander BP. Prevention of choroidal thinning by 0 . $01 \%$ atropine administered $24 \mathrm{~h}$ before exposure to hyperopic blur in young myopes. J Ocul Pharmacol Ther. 2021;37:510-7.

59. Sander BP, Collins MJ, Read SA. Short-term effect of low-dose atropine and hyperopic defocus on choroidal thickness and axial length in young myopic adults. J Ophthalmol. 2019;2019:4782536.

60. Zhao W, Li Z, Hu Y, Jiang J, Long W, Cui D, et al. Short-term effects of atropine combined with orthokeratology (ACO) on choroidal thickness. Cont Lens Anterior Eye. 2021;44:101348.

61. Hao Q, Zhao Q. Changes in subfoveal choroidal thickness in myopic children with $0.01 \%$ atropine, orthokeratology, or their combination. Int Ophthalmol. 2021;41(9):2963-71.

62. Ye L, Shi Y, Yin Y, Li S, He J, Zhu J, et al. Effects of atropine treatment on choroidal thickness in myopic children. Invest Ophthalmol Vis Sci. 2020;61(14):15.

63. Chiang ST, Turnbull PRK, Phillips JR. Additive effect of atropine eye drops and short-term retinal defocus on choroidal thickness in children with myopia. Sci Rep. 2020;10(1):18310.

64. Tan CS, Ouyang Y, Ruiz H, Sadda SR. Diurnal variation of choroidal thickness in normal, healthy subjects measured by spectral domain optical coherence tomography. Invest Ophthalmol Vis Sci. 2012;53(1):261-6.

65. Carr BJ, Mihara K, Ramachandran R, Saifeddine M, Nathanson NM, Stell WK, et al. Myopia-inhibiting concentrations of muscarinic receptor antagonists block activation of alpha2A-adrenoceptors in vitro. Invest Ophthalmol Vis Sci. 2018;59(7):2778-91.

66. Carr BJ, Stell WK. Nitric oxide (NO) mediates the inhibition of form-deprivation myopia by atropine in chicks. Sci Rep. 2016;6(1):9.

67. Mathis U, Feldkaemper M, Wang M, Schaeffel F. Studies on retinal mechanisms possibly related to myopia inhibition by atropine in the chicken. Graefes Arch Clin Exp Ophthalmol. 2020;258(2): 319-33.

68. Öner V, Bulut A, Öter K. The effect of topical antimuscarinic agents on subfoveal choroidal thickness in healthy adults. Eye (Lond). 2016;30(7):925-8.

69. Sander BP, Collins MJ, Read SA. The effect of topical adrenergic and anticholinergic agents on the choroidal thickness of young healthy adults. Exp Eye Res. 2014;128:181-9.

70. Maltsev DS, Kulikov AN, Vasiliev AS. Effect of topical pilocarpine on choroidal thickness in healthy subjects. Optom Vis Sci. 2020;97(6):457-61.

71. Zhou X, Zhang S, Zhang G, Chen Y, Lei Y, Xiang J, et al. Increased choroidal blood perfusion can inhibit form deprivation myopia in guinea pigs. Invest Ophthalmol Vis Sci. 2020;61(13):25.

72. Wu H, Chen W, Zhao F, Zhou Q, Reinach PS, Deng $\mathrm{L}$, et al. Scleral hypoxia is a target for myopia control. Proc Natl Acad Sci U S A. 2018;115(30): E7091-100.

73. Zhou X, Ye C, Wang X, Zhou W, Reinach P, Qu J. Choroidal blood perfusion as a potential "rapid predictive index" for myopia development and progression. Eye Vis (Lond). 2021;8(1):1.

74. Khanal S, Rathod SN, Phillips JR. The acute effect of atropine eye drops on the human full-field electroretinogram. Doc Ophthalmol. 2021;142(3): 315-28.

75. Khanal S, Turnbull PRK, Lee N, Phillips JR. The effect of atropine on human global flash mfERG responses to retinal defocus. Invest Ophthalmol Vis Sci. 2019;60(1):218-25.

76. Xiong S, He X, Zhang B, Deng J, Wang J, Lv M, et al. Changes in choroidal thickness varied by age and refraction in children and adolescents: a 1-year longitudinal study. Am J Ophthalmol. 2020;213: 46-56.

77. Read SA, Alonso-Caneiro D, Vincent SJ. Longitudinal changes in macular retinal layer thickness in pediatric populations: Myopic vs non-myopic eyes. PLoS ONE. 2017;12(6):e0180462.

78. Jin P, Zou H, Xu X, Chang TC, Zhu J, Deng J, et al. Longitudinal changes in choroidal and retinal thicknesses in children with myopic shift. Retina. 2019;39(6):1091-9. 